\title{
Emergency contraception: potential role of ulipristal acetate
}

This article was published in the following Dove Press journal:

International Journal of Women's Health

17 April 2010

Number of times this article has been viewed

\section{Kristina Gemzell-Danielsson Chun-Xia Meng \\ Department of Women's and Children's Health, Division of Obstetrics and Gynecology, Karolinska Institutet, Stockholm, Sweden}

\begin{abstract}
Unintended pregnancy is a global reproductive health problem. Emergency contraception (EC) provides women with a safe means of preventing unwanted pregnancies after having unprotected intercourse. While $1.5 \mathrm{mg}$ of levonorgestrel (LNG) as a single dose or in 2 doses with 12 hours apart is the currently gold standard EC regimen, a single dose of $30 \mathrm{mg}$ ulipristal acetate (UPA) has recently been proposed for EC use up to 120 hours of unprotected intercourse with similar side effect profiles as LNG. The main mechanism of action of both LNG and UPA for EC is delaying or inhibiting ovulation. However, the 'window of effect' for LNG EC seems to be rather narrow, beginning after selection of the dominant follicular and ending when luteinizing hormone peak begins to rise, whereas UPA appears to have a direct inhibitory effect on follicular rupture which allows it to be also effective even when administered shortly before ovulation, a time period when use of LNG is no longer effective. These experimental findings are in line with results from a series of clinical trials conducted recently which demonstrate that UPA seems to have higher EC efficacy compared to LNG. This review summarizes some of the data available on UPA used after unprotected intercourse with the purpose to provide evidence that UPA, a new type of second-generation progesterone receptor modulator, represents a new evolutionary step in EC treatment.
\end{abstract}

Keywords: emergency contraception, ulipristal acetate, levonorgestrel

\section{Introduction}

Despite the availability of highly effective methods of contraception, a great number of pregnancies are unintended. Many women who experience an unintended pregnancy have become pregnant as a result of either lacking of contraceptives or contraceptive failure. Emergency contraception (EC) is defined as the use of any drug or device after unprotected intercourse to prevent an unwanted pregnancy. Although the situations that lead to contraceptive failure are diverse, most women know the reasons why they got pregnant (such as, forgetting the pill, condom slippage) and could thus have used EC to prevent the pregnancy. ${ }^{1}$ Despite of rapidly increasing use, EC is still underutilized worldwide. It has been estimated that millions of unwanted pregnancies could be avoided if EC were widely accessible and properly used, ${ }^{2}$ although its impact on the population seems questionable.,4 Today levonorgestrel (LNG) is the gold standard for oral EC. Recently, a new type of second generation progesterone receptor modulator, ulipristal acetate (UPA), has emerged which represents a new evolutionary step in EC treatment. UPA EC has been shown to be associated with a lower pregnancy rate compared to LNG EC. This review will summarize some of the clinical data available on UPA when used for preventing pregnancy after unprotected intercourse.
Correspondence: Kristina

Gemzell-Danielsson

WHO-Collaborating Center, $\mathrm{Cl}: 05$,

Karolinska University Hospital/Karolinska Institutet, 17176 Stockholm, Sweden

Tel +46-8-5I 1772128

Fax +46-8-51774314

Email kristina.gemzell@ki.se 


\section{Available methods}

Several approaches to EC have been described. Although the copper-bearing intrauterine device (IUD) is the most effective EC method, its widespread use is limited due to logistic and medical reasons. In the late 1970s Yuzpe introduced a regimen consisting of $0.1 \mathrm{mg}$ ethinylestradiol and $0.5 \mathrm{mg}$ LNG, given within 72 hours of the intercourse and repeated after 12 hours. ${ }^{5}$ The Yuzpe regimen was the most commonly used EC method until the late 1990s when it started to be replaced by the administration of LNG. Treatment with LNG $0.75 \mathrm{mg}$, repeated after 12 hours or as a single dose of $1.5 \mathrm{mg}$, was shown to be associated with lower rate of side effects and higher efficacy than the Yuzpe regimen. ${ }^{6-8}$ The efficacy of both regimens decreased with treatment delay. In a subsequent study, the efficacy of a single dose of $10 \mathrm{mg}$ mifepristone was compared to LNG $1.5 \mathrm{mg}$ either in a single dose or in 2 doses 12 hours apart. ${ }^{9}$ Pregnancy rates did not differ between mifepristone and LNG treatment in divided or single doses when taken within 5 days of unprotected intercourse. Side effects were mild and similar between treatment groups. The efficacy of mifepristone when used for EC has been shown to be dose dependent. ${ }^{10}$ Although mifepristone (mid or high doses) has higher efficacy than LNG, ${ }^{10}$ the potential for mifepristone EC is limited due to social and political reasons since it can be used and is available as an abortifacient if combined with a prostaglandin analogue. To date, mifepristone in low doses $(10,25$ or $50 \mathrm{mg})$ for $\mathrm{EC}$ is available only in China.

Following these studies and until now, LNG $1.5 \mathrm{mg}$ as a single dose taken as soon as possible and within 72 hours of unprotected intercourse has become the recommended regimen for oral EC pill. Although EC with $1.5 \mathrm{mg}$ LNG has contributed to the prevention of unwanted pregnancies, it has limitations in terms of efficacy which drops significantly with the time elapsed since unprotected intercourse. Pregnancy rates with LNG EC in the first 24 hours are approximately
$1.5 \%$, but increase to $2.6 \%$ during the period of 48 to 72 hours after exposure. . $, 9,11,12^{2}$

\section{Ulipristal acetate (UPA)}

Ulipristal acetate, also referred to as CDB-2914 or VA2914, is a novel orally active selective progesterone receptor modulator (SPRM) with the chemical name $17 \alpha-$ acetoxy-11 $\beta$-[4- $N, N$-dimethylaminophenyl-19-norpregna4,9-diene-3, 20-dione. ${ }^{13-16}$ It is a white to yellow crystal powder, which is insoluble in water $(3 \mathrm{mg} / 100 \mathrm{~mL})$ with the molecular weight of 475.6. The molecular formula of UPA is $\mathrm{C}_{30} \mathrm{H}_{37} \mathrm{NO}_{4}$ (Pubchem, CID: 130904).

Ulipristal acetate is a derivative of 19-norprogesterone and was developed to have enhanced specificity for progesterone receptor. Pre-clinical studies indicate that UPA binds to human progesterone, glucocorticoid and androgen receptors at approximately $6,1.5$ and 0.2 times the affinity of the endogenous ligands and shows in vivo anti-glucocorticoid and anti-androgen activity at doses approximately 50 -fold greater than those needed for anti-progestin effect. Its binding and antagonist potency with respect to the glucocorticoid receptor is significantly reduced compared to that of mifepristone, indicating that UPA belongs to a new type of dissociated progesterone receptor modulators that have reduced antiglucorticoid activity. ${ }^{13,15-17}$ The chemical structure of progesterone, LNG and UPA is depicted in Figure 1.

The pharmacodynamic properties of UPA in humans reflect the mixed progesterone agonistic/antagonistic profile of the molecule. ${ }^{17}$ In addition to development for an EC use, UPA is also being developed in other indications, including treatment of uterine fibroids..$^{18}$

Following oral administration of a single $30 \mathrm{mg}$ dose, UPA is rapidly absorbed, with a peak plasma concentration of $176 \pm 89 \mathrm{ng} / \mathrm{mL}$ occurring approximately 0.5 to 3 hours after ingestion, depending on whether the drug is taken during the fasting state or after a meal. Doses of unmicronized 1,

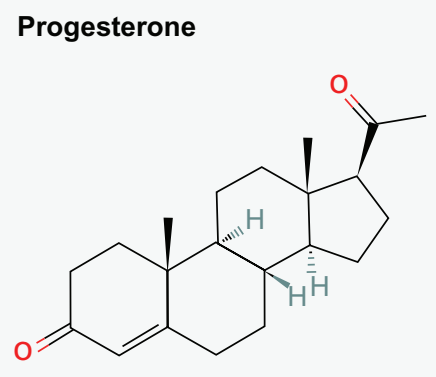

Levonorgestrel

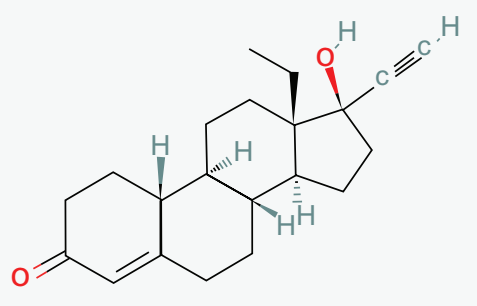

Ulipristal acetate

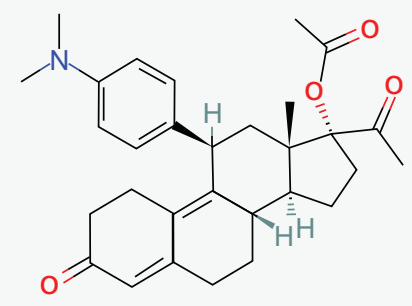

Figure I The chemical structures for progesterone, levonorgestrel and ulipristal acetate. 
10 and $50 \mathrm{mg}$ UPA exhibit proportional increases in peak serum levels, but serum levels from higher doses, 100 and $200 \mathrm{mg}$, are not dose-dependent, suggesting saturation of carrier sites. ${ }^{17}$

Absorption of UPA is pH-dependent. High binding ( $>98 \%$ ) occurs to plasma proteins. The compound is extensively metabolized by cytochrome P450 3A4 (CYP3A4) in the liver, and the principal metabolites formed are the mono- and di-demethylated derivatives, of which the former, 3877A, is pharmacologically active. The terminal half-life in plasma is $32.4 \pm 6.3$ hours (data on file).

In vitro studies have shown that CYP3A4 is primarily responsible for the metabolism of UPA (SPC). Although specific drug-drug interaction studies have not been performed, it is possible that inducers of CYP3A4, eg, rifampin, dexamethasone, St. John's wort, and certain anticonvulsants (phenytoin, phenobarbital, carbamazepine), may induce the metabolism of UPA and cause lowered plasma levels. Furthermore, inhibitors of CYP3A4, eg, the HIV protease inhibitors, itraconazole, erythromycin, and grapefruit juice, may inhibit the metabolism of UPA and cause increased plasma levels.

\section{The fertile window}

It is only during a limited period, from 5 days before to 1 day after ovulation, that unprotected intercourse may result in a pregnancy. ${ }^{19-21}$ However, in assessing EC efficacy, the variability of ovulation has to be taken into account. It was calculated that the possibility of late ovulation produces a persistent risk of pregnancy even into the sixth week of the cycle. ${ }^{22}$ A major discrepancy between women's self-report of stage of the menstrual cycle and the dating calculation based on endocrine data was shown in a clinical trial on the effectiveness of EC. ${ }^{23}$ Studies have also shown that the frequency of intercourse rose during the follicular phase, peaking at ovulation and declining abruptly thereafter. The 6 consecutive days with most frequent intercourse corresponded with the 6 fertile days of the menstrual cycle. ${ }^{24}$ Therefore, it is likely that in a population of women administered EC, a significant proportion are at least at some risk of pregnancy. Therefore, EC should be recommended at any time during the cycle after any act of unprotected intercourse or contraceptive accident.

\section{Methods to determine EC efficacy}

Pearl index for measuring contraceptive efficacy cannot be used for evaluating the efficacy of an EC. In the trials, women who presented within the defined time window after unprotected intercourse were administered EC, and they were followed-up to determine whether or not they became pregnant. Women included in these studies had, by definition, varying degrees of pregnancy risk, depending on how close the index act of intercourse occurred to the fertile window in the cycle (the 6 days leading up to and including the day of ovulation as discussed above) and how fertile they (and their partners) were, depending on age and other physiological characteristics. In addition, it is extremely difficult to predict with sufficient accuracy where a woman is in her menstrual cycle at the time of unprotected intercourse. Therefore 2 complementary parameters to provide estimates of the EC efficacy have been proposed:

i) The first is the pregnancy rate, defined as the number of pregnancies observed at follow-up divided by the total number of women exposed to $\mathrm{EC}$ in a given trial. Pregnancy rate is an objective measure that includes all subjects exposed to EC but does not take into account their degree of risk of pregnancy and therefore potentially overestimates EC efficacy, even though studies have shown that the frequency of intercourse in the menstrual cycle peaks during the fertile window, rendering it likely that in a population of women administered EC, a significant proportion are at least at some risk of pregnancy. ${ }^{24}$ When measured in large populations of presumably fertile women (women aged $\leq 35$ with regular menstrual cycles), the pregnancy rate is therefore a fairly good estimate of the overall risk of pregnancy after EC intake.

ii) The second is prevented fraction (contraceptive effectiveness), defined as one minus the number of pregnancies observed divided by the number of pregnancies expected in the absence of EC treatment $\left(1-\mathrm{P}_{\text {obs }} / \mathrm{P}_{\text {exp }}\right)$. It measures the proportion of pregnancies avoided by EC treatment. The number of expected pregnancies is determined by assigning a known conception probability to each patient, according to the cycle day of intercourse relative to ovulation. ${ }^{19,21}$ This calculation requires accurate information for each woman included in the trial about the date of her last menstrual period. The length of luteal phase being a constant 14 days, the date of expected ovulation can be estimated assuming that the women in the study have regular menstrual cycles of a known length and that she correctly remembers her last menstrual period.

\section{Mechanisms of action of EC pills}

Introduction of EC pills in many countries has generated much controversy and litigation. One of the main barriers to widespread use of EC around the world is the confusion about potential mechanisms of action, such as concern that 
EC might impair implantation or disrupt an implanted fetus. Emergency contraception is also frequently confused with induced abortion. In many developing countries, the lack of knowledge about and access to EC may result in women resorting to unsafe abortions, which contribute significantly to maternal mortality and morbidity. Therefore adequate information on the mechanism of action of EC is crucial.

\section{LNG}

If administered at least 2 days prior to the luteinizing hormone (LH) surge, LNG causes either a delay or an inhibition of the LH surge, therefore delays or inhibits ovulation in women. ${ }^{25-28}$ However, if given when LH has already started to rise, LNG cannot prevent ovulation. ${ }^{28,29}$ Furthermore, LNG in a regimen used for EC does not affect endometrial development or progesterone level. ${ }^{25,27}$ Human embryo implantation when studied in vitro is unaffected by LNG. ${ }^{30}$ Animal studies confirm that LNG does not affect fertilization or implantation. ${ }^{31,32}$ These experimental findings are in line with the clinical data on LNG EC. ${ }^{23}$ In this clinical trial, 99 women were recruited at the time they presented with a request for $\mathrm{EC}$ and the effectiveness of EC pill when taken before and after ovulation was determined. A blood sample was taken immediately prior to ingestion of LNG $1.5 \mathrm{mg}$ in a single dose for estimation of serum LH, estradiol and progesterone levels to calculate the day of ovulation. Three women became pregnant despite taking LNG (pregnancy rate, 3.0\%). All three women who became pregnant had unprotected intercourse between Days -1 and 0 and took the LNG pill on Day +2 , based on endocrine data. Day 0 was taken as ovulation day. Among 17 women who had intercourse in the fertile period of the cycle and took the LNG pill after ovulation occurred (on Days +1 to +2 ), 3 or 4 pregnancies could have been expected and three were observed. Among 34 women who had intercourse on Days -5 to -2 of the fertile period and took the pill before or on the day of ovulation, four pregnancies could have been expected, but none were observed. Taken together an increasing amount of data support the concept that LNG EC has no effect on post-ovulation events. Furthermore pregnancies occurring due to unprotected intercourse during the window when LNG EC lacks efficacy (after LH has started to rise until the day after ovulation or at the time of implantation) do not show any adverse effects from LNG exposure. ${ }^{33,34}$

\section{UPA}

Progesterone plays a key role during ovulation. Mice lacking progesterone receptor gene fail to ovulate due to a defect in follicular rupture. ${ }^{35}$ To identify pathways that modulate ovulation, gene expression profiling was performed using ovaries from mice subjected to gonadotropin-induced superovulation in the presence and in the absence of UPA. Prominent among the genes that were down-regulated in response to UPA was endothelin-2, a potent vasoactive molecule. Endothelin-2 mRNA was transiently induced in mural granulosa cells of the preovulatory follicles immediately preceding ovulation. This induction was absent in the ovaries of progesterone receptor null mice. Furthermore, mice treated with an endothelin selective antagonists of endothelin receptor-B exhibited a dramatic $(>85 \%)$ decline in the number of released oocytes. ${ }^{36}$

The biological effects of UPA vary according to the time of the menstrual cycle that the drug is given and the doses. Singles doses of UPA administered during the mid follicular phase suppress leading follicle growth, causing a dose-dependent delay in folliculogenesis and suppression of plasma estradiol. At higher does, a new leading follicle is often recruited. ${ }^{17,37}$ In a series of clinical trials the effect of UPA at different follicular diameters and in relation to the LH peak and ovulation was studied. ${ }^{38}$ When given prior to the LH rise, UPA inhibited $100 \%$ of follicular ruptures. When the size of the leading follicle was at least $18 \mathrm{~mm}$, follicular rupture failed to occur within the 5 and 6 days following UPA treatment in $20(59 \%)$ and $15(44 \%)$ subjects respectively. Even on the day of the LH peak UPA could delay ovulation for 24 to 48 hours after administration. Taken together these studies demonstrate that UPA may have a direct inhibitory effect on follicular rupture. This allows UPA to be effective even when administered immediately before ovulation when LH has already started to rise, a time when use of LNG or Yuzpe is too late for ovulation inhibition (Figure 2).

In a study comparing early luteal phase treatement with placebo, 10, 50 or $100 \mathrm{mg}$ unmicronized UPA, a significant delay in endometrial maturation was seen in the 50 and $100 \mathrm{mg}$ groups compared to the placebo and the $10 \mathrm{mg}$ group upon biopsy 4 to 6 days after ovulation. ${ }^{17,37,39}$ Treatment with UPA resulted in a significant dose-dependent decrease in endometrial thickness as well as an increase in glandular P receptors. ${ }^{39}$

On average, UPA tends to lengthen the menstrual cycle by approximately 1 to 2 days although the amount of delay varies with timing in the menstrual cycle and dose. Women who received $50 \mathrm{mg}$ unmicronized UPA experienced an average of 2 to 3 days delay in menses. This delay was dependent on when in the menstrual cycle the drug was taken, with the least effect occurring at about mid-cycle. Median values reflect a menses delay of 1 to 3 days when drug is taken during the follicular phase, little or no effect on cycle length when 


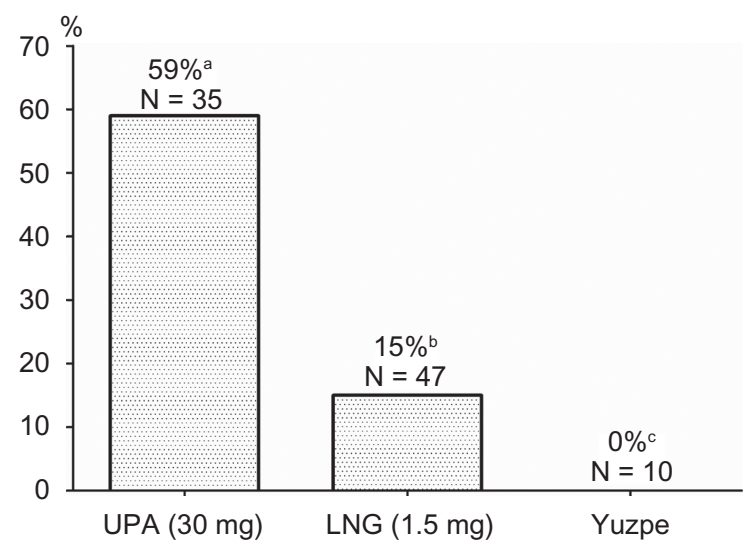

Figure 2 Proportion of cycles without follicular rupture within the 5-day period following administration of emergency contraceptive pills with a follicular diameter of $\geq 18 \mathrm{~mm}$. (UPA: ulipristal acetate, $30 \mathrm{mg}$; LNG: levonorgestrel, $1.5 \mathrm{mg}$ in a single dose).

${ }^{\mathrm{a}}$ Data from Croxatto et $\mathrm{al}^{38}$; ${ }^{\mathrm{b}} \mathrm{Data}$ from Croxatto et $\mathrm{al}^{28}$ and Massai et $\mathrm{al}^{29}$; c Data from Croxatto et al..$^{53}$

taken in the periovulatory period or the early to mid-luteal phase, and a tendency to delay menses when taken in the late luteal phase. However, $200 \mathrm{mg}$ taken at the mid-luteal phase induced early menses, indicating that the changes in menstrual cycle length are likely to be dose-dependent. ${ }^{17}$

\section{Mifepristone}

The effect of mifepristone is well known to be depend on time of treatment during the menstrual cycle and the dose given. A variety of regimens with a single dose as low as $10 \mathrm{mg}$ have been shown to interrupt follicle development and thus delay or inhibit ovulation. ${ }^{27,40-42}$ While higher doses affect endometrial receptivity and prevent implantation, ${ }^{30,43-45} 10 \mathrm{mg}$ mifepristone has little or no effect on the endometrium. ${ }^{27}$

\section{Efficacy of UPA}

A randomized controlled double-blinded phase II trial comparing the efficacy of $50 \mathrm{mg}$ unmicronized UPA with LNG ( $0.75 \mathrm{mg}$ twice) used within 72 hours of intercourse which was designed as a non-inferiority study included 1549 women. ${ }^{46}$ A $50 \mathrm{mg}$ unmicronized capsule of UPA is pharmacokinetically equal to $30 \mathrm{mg}$ micronized drug substance formulated in a tablet (data on file). This trial showed that UPA was indeed statistically non-inferior to LNG (noninferiority margin of $2 \%$ ). In addition, the results showed a trend towards higher efficacy of UPA in comparison to LNG. Of particular importance, the results showed that while the efficacy of LNG tended to be lower on the third day (48 to 72 hours after intercourse) than the efficacy when used within 48 hours (as expected from previous trials with LNG), this was not the case in the women treated with UPA. Thus, a sustained efficacy of UPA was demonstrated up to 72 hours after unprotected intercourse whereas efficacy with LNG decreased over time. ${ }^{46}$ Pregnancy rates in the two groups were $0.9 \%$ (95\% confidence interval [CI] $0.2 \%$ to $1.6 \%$ ) and $1.7 \%$ ( $95 \%$ CI $0.8 \%$ to $2.6 \%$ ), respectively. The difference between treatments of $-0.8 \%$, with an upper limit of the $97.5 \%$ onetailed CI of $0.77 \%$, was statistically non-inferior. When calculating the contraceptive effectiveness (prevented fraction) of UPA and LNG, women treated with UPA experienced an $85 \%$ reduction in the number of pregnancies whereas LNG users had a reduction of $69 \%$.

A more recent phase III, non-inferiority trial confirmed the efficacy of UPA for EC up to 120 hours of unprotected intercourse. ${ }^{47}$ In this study, women presenting for EC within 120 hours of unprotected intercourse were randomized to be given a single dose of either $30 \mathrm{mg}$ UPA or $1.5 \mathrm{mg} \mathrm{LNG}$. A total of 1899 women were evaluated for efficacy. Pregnancy rates were $1.8 \%$ (95\% CI 1.0\% to . $0 \%$ ) for UPA and $2.6 \%$ (95\% CI $1.7 \%$ to $3.9 \%$ ) for LNG with an odds ratio (OR) (UPA versus LNG) of 0.57 (95\% CI 0.29 to 1.09$)$.

The efficacy of a $30 \mathrm{mg}$ UPA up to 120 hours after unprotected intercourse was also evaluated in a phase III openlabel clinical trial. ${ }^{48}$ Only women who presented between 48 hours and 120 hours after unprotected intercourse were eligible. The observed pregnancy rate following intake of UPA was $2.1 \%$ (95\% CI $1.4 \%$ to $3.1 \%$ ), which was statistically inferior to both estimated pregnancy rate of $5.5 \%$ and a predefined clinical irrelevance threshold. In addition, analysis trend did not reveal any increase of pregnancy rate over time up to 120 hours. There were no significant safety issues.

The databases from the two randomized controlled trials comparing UPA with LNG EC ( $\mathrm{n}=1549$ women treated $<72$ hours after unprotected intercourse plus 1899 women treated $<120$ hours) were merged in a meta-analysis including the primary efficacy populations defined in each study. ${ }^{47}$ Comparisons were done for different time windows of treatment in relation to unprotected intercourse. In analysis of the total 3445 women it appeared that UPA was statistically superior to LNG for use within 120 hours (OR 0.55, 95\% CI 0.32 to $0.93)$. Moreover, UPA was statistically superior to LNG for intake within 24 hours of intercourse $(n=1184)$ with an OR of 0.35 (95\% CI 0.11 to 0.93 ). The meta-analysis provides evidence that UPA is statistically more effective than LNG for early as well as late use of EC. 


\section{Bleeding profiles and adverse events}

In the phase II randomized controlled trial comparing UPA to LNG, menstrual periods after the use of UPA or LNG were of normal duration and intensity. ${ }^{46} \mathrm{~A}$ reduction of 4 to 19 days in the menstrual interval during the treatment cycle occurred in $25 \%$ of LNG users and $17 \%$ of UPA users $(P<0.001)$. On average, post-treatment cycle length was 2.6 days longer than anticipated date with UPA and 2.1 days shorter with LNG. While a shortening of the cycle may be the result of an inhibition of ovulation, a delay in menses subsequent to treatment with UPA is in line with a postponement of ovulation which is one important mechanism of action of this treatment. In addition, LNG users exhibited shortening of cycle length if the pill was taken in the proliferative phase, less shortening if taken at ovulation or in the early secretory phase and lengthening of the cycle when administered in the mid to late secretory phase. In contrast, no such trend was found between the different cycle phases for women who took UPA. ${ }^{46}$

Adverse events were mainly mild or moderate, shortlasting, self-limiting and similar with both EC pills. The most frequently observed side effects included lower abdominal pain, nausea, and headache.

\section{Pregnancy and breast feeding}

Ulipristal acetate in a single $30 \mathrm{mg}$ dose has been shown to be safe and effective for EC in clinical studies prior to registration in Europe. A single dose of $30 \mathrm{mg}$ UPA for EC (ellaOne ${ }^{\circledR}$; HRA-Pharma, Paris, France) was approved by European Medicines Agency (EMEA) in May 2009. So far only very few pregnancies have been exposed to UPA. Collection of further data is therefore needed. In an agreement between the EMEA and the market authorization holder, HRA-Pharma, a registry has been created to collect information on any pregnancy exposed to UPA, for example an unrecognized pregnancy before intake or as a result of treatment failure. The goal is to collect all data about pregnancy outcomes in women exposed to UPA.

So far it is unknown whether UPA is excreted in human milk as studies are lacking. As UPA is a lipophilic compound it may theoretically be excreted in human milk. Therefore, until more data is available breast-feeding is not recommended in the 36 hours following UPA intake. For LNG the corresponding recommendation is to avoid breast-feeding for at least 8 hours but not more than 24 hours after LNG intake. ${ }^{49}$

\section{Posology}

The approved treatment consists of 1 tablet of $30 \mathrm{mg}$ UPA to be administered orally as soon as possible and no later than 120 hours (5 days) after unprotected intercourse. The tablet can be taken with or without food. Based on the pharmacokinetics it is recommended that if vomiting occurs within 3 hours of UPA intake, another tablet should be taken. Pregnancy should be excluded before UPA is administered. Contraindications to UPA are similar to those of LNG-EC and include hypersensitivity to the active substance or any of the constituents and pregnancy (SMPC ellaOne ${ }^{\circledR}$ ).

\section{Interactions}

Since UPA binds the progesterone receptor with high affinity, it may interfere with the action of progestogen-containing drugs. The data on combined action of UPA and LNG used for EC is so far unavailable. Supplementary administration of a SPRM improved bleeding patterns in women using progestogen-only pill (POP) regimen ${ }^{50}$ or subdermal contraceptive implants releasing LNG (Norplant). ${ }^{51}$ The improvement in bleeding pattern could be either by a direct effect of antiprogestin on the endometrium, as suggested by the effect on steroid receptor expression, or by inducing ovulation. ${ }^{52}$ An increased ovulation rate may jeopardize contraception, Therefore, theorectically, concomitant use of UPA with LNG EC is not recommended. Furthermore, at least theoretical, the effectiveness of combined hormonal contraceptives and progestin only contraceptive may be reduced by UPA. Back-up barrier methods should be recommended for women relying on any form of hormonal contraceptives until her next menses.

Ulipristal acetate is metabolized by CYP3A4 in vitro and its absorption is $\mathrm{pH}$-dependent. No specific drug interaction studies have been performed in vivo. However, CYP3A4 inducers (eg, rifampicin, phenytoin, phenobarbital, carbamazepine, ritonavir, St. John's wort) may theoretically reduce plasma concentrations of UPA and result in a decrease in efficacy. Concomitant use is therefore not recommended. Enzyme induction wears off slowly and effects on the plasma concentrations of UPA may occur even if a woman has stopped taking an enzyme inducer within the previous 2 to 3 weeks.

Concomitant administration of medicinal products that increase gastric $\mathrm{pH}$ (eg, proton pump inhibitors, antacids and $\mathrm{H}_{2}$-receptor antagonists) may reduce plasma concentrations of UPA and may result in a decrease in efficacy. Concomitant use is therefore not recommended. However food interaction studies show that UPA can be taken with or without food. 


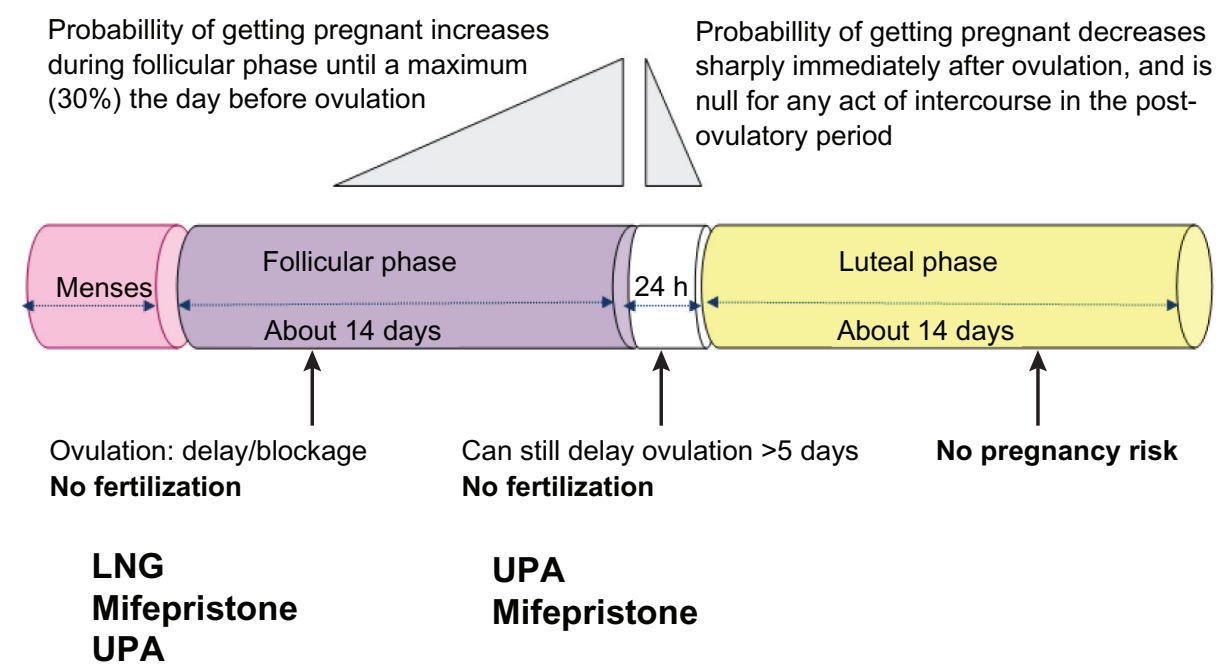

Figure 3 The fertile window and effects of emergency contraceptive pills. If administered before ovulation has been triggered, ulipristal acetate (UPA, 30 mg), levonorgestrel (LNG, I.5 mg), and mifepristone (10 mg) act by delaying or inhibiting ovulation. If administered when the luteinzing hormone peak has already started to rise, only UPA or probably mifepristone $(10 \mathrm{mg})$ as well can delay ovulation.

\section{Conclusion and recommendations}

Emergency contraception is the only method that women can use after having sexual intercourse without contraceptive protection to avoid becoming pregnant. It could be a powerful means to prevent unwanted pregnancies if widely available and acceptable.

UPA is a first-in-class progesterone receptor modulator specifically developed for EC. It has been demonstrated to be highly efficacious versus LNG for intake within 24 hours as well as for intake up to 72 hours after unprotected intercourse. Furthermore, UPA maintains its efficacy up to 5 days after unprotected intercourse, matching the survival time of sperms. UPA $30 \mathrm{mg}$ is as well-tolerated as LNG. Therefore UPA represents a veritable breakthrough in emergency contraceptive technology with a clear-cut medical advantage over LNG.

Although the main mechanism of action of both LNG and UPA is preventing follicular rupture and ovulation (Figure 3), the 'window of effect' for LNG seems to be rather narrow, beginning after selection of the dominant follicle, and ending when LH begins to rise. In contrast, UPA has been demonstrated to have a direct inhibitory effect on follicular rupture. This allows UPA to be effective even when administered shortly before ovulation when the LH surge has already started to rise, a time period when use of LNG is no longer effective. The differences in mechanisms of action explain the higher efficacy demonstrated for UPA to prevent pregnancy for both early and late use of EC. UPA may not be the first line EC for all users of hormonal contraceptives, since it increases their vulnerability to pregnancy significantly for the rest of the cycle. However, if users are willing to use back up barrier contraception until the next menses, UPA should be recommended.

Thus to help women prevent an unwanted pregnancy after unprotected intercourse at any moment during the menstrual cycle, a single dose of $30 \mathrm{mg}$ UPA should be recommended for use as soon as possible, and no later than 120 hours (5 days) after intercourse. If vomiting occurs within 3 hours of UPA intake, another tablet should be taken. Pregnancy should be excluded before ECP is administered. Further acts of unprotected intercourse after ECP use should be avoided to prevent the risk of timing a delayed follicular rupture and ovulation.

\section{Acknowledgments/disclosures}

The authors reports no conflicts of interest in this work. The authors are supported by grants from Karolinska Institutet (KID grant), Swedish Medical Research Council (2003-3869, K2007-54X-14212-06-3) and Karolinska Institutet Stockholm City County/Karolinska Institutet (ALF).

\section{References}

1. Moreau C, Bajos N, Trussell J. The impact of pharmacy access to emergency contraceptive pills in France. Contraception. 2006;73(6): $602-608$

2. Consensus statement on emergency contraception. Contraception. 1995;52(4):211-213.

3. Raymond EG, Trussell J, Polis CB. Population effect of increased access to emergency contraceptive pills: a systematic review. Obstet Gynecol. 2007;109(1):181-188. 
4. Polis CB, et al. Advance provision of emergency contraception for pregnancy prevention (full review). Cochrane Database Syst Rev. 2007(2):CD005497.

5. Yuzpe AA, Lancee WJ. Ethinylestradiol and dl-norgestrel as a postcoital contraceptive. Fertil Steril. 1977;28(9):932-936.

6. Task Force on Postovulatory Methods of Fertility Regulation. Randomised controlled trial of levonorgestrel versus the Yuzpe regimen of combined oral contraceptives for emergency contraception. Lancet. 1998;352(9126):428-433.

7. von Hertzen H, Piaggio G, Van Look PF. Emergency contraception with levonorgestrel or the Yuzpe regimen. Task Force on Postovulatory Methods of Fertility Regulation. Lancet. 1998;352(9144):1939.

8. Raymond $\mathrm{E}$, et al. Minimum effectiveness of the levonorgestrel regimen of emergency contraception. Contraception. 2004;69(1):79-81.

9. von Hertzen $\mathrm{H}$, et al. Low dose mifepristone and two regimens of levonorgestrel for emergency contraception: a WHO multicentre randomised trial. Lancet. 2002;360(9348):1803-1810.

10. Cheng L, et al. Interventions for emergency contraception. Cochrane Database Syst Rev. 2008(2):CD001324.

11. Piaggio G, et al. Timing of emergency contraception with levonorgestrel or the Yuzpe regimen. Task Force on Postovulatory Methods of Fertility Regulation. Lancet. 1999;353(9154):721.

12. Ho PC, Kwan MS. A prospective randomized comparison of levonorgestrel with the Yuzpe regimen in post-coital contraception. Hum Reprod. 1993;8(3):389-392.

13. Attardi BJ, et al. CDB-4124 and its putative monodemethylated metabolite, CDB-4453, are potent antiprogestins with reduced antiglucocorticoid activity: in vitro comparison to mifepristone and CDB-2914. Mol Cell Endocrinol. 2002;188(1-2):111-123.

14. Blithe DL, et al. Development of the selective progesterone receptor modulator CDB-2914 for clinical indications. Steroids. 2003; 68(10-13):1013-1017.

15. Gainer EE, Ulmann A. Pharmacologic properties of CDB(VA)-2914. Steroids. 2003;68(10-13):1005-1011.

16. Attardi BJ, et al. In vitro antiprogestational/antiglucocorticoid activity and progestin and glucocorticoid receptor binding of the putative metabolites and synthetic derivatives of CDB-2914, CDB-4124, and mifepristone. J Steroid Biochem Mol Biol. 2004;88(3):277-288.

17. Blithe DL, et al. Development of the selective progesterone receptor modulator CDB-2914 for clinical indications. Steroids. 2003; 68(10-13):1013-1017.

18. Levens ED, et al. CDB-2914 for uterine leiomyomata treatment: a randomized controlled trial. Obstet Gynecol. 2008;111(5):1129-1136.

19. Wilcox AJ, Weinberg CR, Baird DD. Timing of sexual intercourse in relation to ovulation. Effects on the probability of conception, survival of the pregnancy, and sex of the baby. $N$ Engl J Med. 1995;333(23):1517-1521

20. Dixon GW, et al. Ethinyl estradiol and conjugated estrogens as postcoital contraceptives. JAMA. 1980;244(12):1336-1339.

21. Trussell J, Rodriguez G, Ellertson C. New estimates of the effectiveness of the Yuzpe regimen of emergency contraception. Contraception. 1998;57(6):363-369.

22. Trussell J, et al. Estimating the effectiveness of emergency contraceptive pills. Contraception. 2003;67(4):259-265.

23. Novikova N, et al. Effectiveness of levonorgestrel emergency contraception given before or after ovulation - a pilot study. Contraception. 2007;75(2):112-118.

24. Wilcox AJ, et al. On the frequency of intercourse around ovulation: evidence for biological influences. Hum Reprod. 2004;19(7): 1539-1543.

25. Durand M, et al. On the mechanisms of action of short-term levonorgestrel administration in emergency contraception. Contraception. 2001;64(4):227-234.

26. Marions L, et al. Effect of emergency contraception with levonorgestrel or mifepristone on ovarian function. Contraception. 2004;69(5):373-377.
27. Marions L, et al. Emergency contraception with mifepristone and levonorgestrel: mechanism of action. Obstet Gynecol. 2002;100(1): 65-71.

28. Croxatto HB, et al. Pituitary-ovarian function following the standard levonorgestrel emergency contraceptive dose or a single $0.75-\mathrm{mg}$ dose given on the days preceding ovulation. Contraception. 2004;70(6): 442-450.

29. Massai MR, et al. Does meloxicam increase the incidence of anovulation induced by single administration of levonorgestrel in emergency contraception? A pilot study. Hum Reprod. 2007;22(2):434-439.

30. Lalitkumar PG, et al. Mifepristone, but not levonorgestrel, inhibits human blastocyst attachment to an in vitro endometrial three-dimensional cell culture model. Hum Reprod. 2007;22(11):3031-3037.

31. Muller AL, Llados CM, Croxatto HB. Postcoital treatment with levonorgestrel does not disrupt postfertilization events in the rat. Contraception. 2003;67(5):415-419.

32. Ortiz ME, et al. Post-coital administration of levonorgestrel does not interfere with post-fertilization events in the new-world monkey Cebus apella. Hum Reprod. 2004;19(6):1352-1356.

33. Meng CX, et al. Expressions of steroid receptors and Ki67 in firsttrimester decidua and chorionic villi exposed to levonorgestrel used for emergency contraception. Fertil Steril. 2009;91(4 Supp1): $1420-1423$

34. Zhang L, et al. Pregnancy outcome after levonorgestrel-only emergency contraception failure: a prospective cohort study. Hum Reprod. 2009;24(7):1605-1611.

35. Lydon JP, et al. Mice lacking progesterone receptor exhibit pleiotropic reproductive abnormalities. Genes Dev. 1995;9(18):2266-2278.

36. Palanisamy GS, et al. A novel pathway involving progesterone receptor, endothelin-2, and endothelin receptor B controls ovulation in mice. Mol Endocrinol. 2006;20(11):2784-2795.

37. Stratton P, et al. A single mid-follicular dose of CDB-2914, a new antiprogestin, inhibits folliculogenesis and endometrial differentiation in normally cycling women. Hum Reprod. 2000;15(5):1092-1099.

38. Croxatto HB, et al. The effects of immediate pre-ovulatory administration of $30 \mathrm{mg}$ ulipristal acetate on follicular rupture. in 8th Congress of the European Society of Gynecology. Sep 10-13, 2009; Rome, Italy.

39. Stratton P, et al. Endometrial effects of a single early luteal dose of the selective progesterone receptor modulator CDB-2914. Fertil Steril. 2009 Feb 5. [Epub ahead of print].

40. Shoupe D, et al. Effects of the antiprogesterone RU 486 in normal women. II. Administration in the late follicular phase. Am J Obstet Gynecol. 1987;157(6):1421-1426.

41. Ledger WL, et al. Inhibition of ovulation by low-dose mifepristone (RU 486). Hum Reprod. 1992;7(7):945-950.

42. van der Stege JG, et al. Effects of a preovulatory single low dose of mifepristone on ovarian function. Eur J Contracept Reprod Health Care. 2006;11(2):104-108.

43. Gemzell-Danielsson K, et al. Effects of a single post-ovulatory dose of RU486 on endometrial maturation in the implantation phase. Hum Reprod. 1994;9(12):2398-2404.

44. Gemzell-Danielsson K, et al. Early luteal phase treatment with mifepristone (RU 486) for fertility regulation. Hum Reprod. 1993;8(6):870-873.

45. Swahn ML, Gemzell K, Bygdeman M. Contraception with mifepristone. Lancet. 1991;338(8772):942-943.

46. Creinin MD, et al. Progesterone receptor modulator for emergency contraception: a randomized controlled trial. Obstet Gynecol. 2006;108(5):1089-1097.

47. Glasier AF, et al. Ulipristal acetate versus levonorgestrel for emergency contraception: a randomised non-inferiority trial and meta-analysis. Lancet Online Jan 29, 2010.

48. Fine P, Mathé H, Ginde S, Cullins V, Morfesis J, Gainer E. Ulipristal acetate taken 48-120 hours after intercourse for emergency contraception. Obstet Gynecol. 2010;115:257-263. 
49. Gainer E, et al. Levonorgestrel pharmacokinetics in plasma and milk of lactating women who take $1.5 \mathrm{mg}$ for emergency contraception. Hum Reprod. 2007;22(6):1578-1584.

50. Gemzell-Danielsson K, et al. Improving cycle control in progestogenonly contraceptive pill users by intermittent treatment with a new antiprogestogen. Hum Reprod. 2002;17(10):2588-2593.

51. Cheng L, et al. Once a month administration of mifepristone improves bleeding patterns in women using subdermal contraceptive implants releasing levonorgestrel. Hum Reprod. 2000;15(9):1969-1972.
52. Glasier AF, et al. Administration of an antiprogesterone up-regulates estrogen receptors in the endometrium of women using Norplant: a pilot study. Fertil Steril. 2002;77(2):366-372.

53. Croxatto HB, Fuentealba B, Brache V, et al. Effects of the Yuzpe regimen, given during the follicular phase, on ovarian function. Contraception. 2002;65(2):121-128.

\section{Publish your work in this journal}

The International Journal of Women's Health is an international, peerreviewed open-access journal publishing original research, reports, reviews and commentaries on all aspects of women's healthcare including gynecology, obstetrics, and breast cancer. Subject areas include Chronic conditions (migraine headaches, arthritis, osteoporosis);
Endocrine and autoimmune syndromes; Sexual and reproductive health; Psychological and psychosocial conditions. The manuscript management system is completely online and includes a very quick and fair peer-review system. Visit http://www.dovepress.com/ testimonials.php to read real quotes from published authors.

Submit your manuscript here: http://www.dovepress.com/international-journal-of-womens-health-journal 